\title{
Relação entre coloração e atividade antibacteriana do mel da Bahia
}

\author{
Andrezza Lóren de Góes Nascimento ${ }^{1 *}$ \& Raquel Guimarães Benevides ${ }^{2, a}$
}

${ }^{1}$ Departamento de Ciências Biológicas, Universidade Estadual de Feira de Santana, Feira de Santana, Bahia, Brasil.

${ }^{2}$ Programa de Pós-Graduação em Biotecnologia, Departamento de Ciências Biológicas, Universidade Estadual de Feira de Santana, Feira de Santana, Bahia, Brasil.

\begin{abstract}
Resumo - O mel é um alimento de consistência e coloração variada elaborado pelas abelhas a partir de matéria-prima coletada nas flores, o néctar. Possui uma composição química complexa, a qual depende de vários fatores, principalmente de origem botânica e climática, e uma escala de cores para o mel foi estabelecida. Neste estudo, avaliamos a relação entre a cor de 10 amostras de méis coletados no estado da Bahia e sua atividade contra três espécies de bactérias: Escherichia coli, Pseudomonas aeruginosa e Staphylococcus aureus. Verificou-se potencial antibacteriano em todas as amostras e uma relação significativa entre coloração e atividade microbiana frente a Staphylococcus aureus, revigorando a hipótese de que méis mais escuros tendem a apresentar maior potencial antibacteriano.
\end{abstract}

Palavras-chave adicionais: Apis mellifera, bactericida, resistência.

\begin{abstract}
Relationship between color and antibacterial activity of honey from Bahia, Brazil) - Honey is a material of varied consistency and color, produced by bees from material collected in flowers, the nectar. It has a complex chemical composition, which depends on several factors, mainly of botanical and climatic origin, and a color scale for honey has been established. In this study, we evaluated the relationship between the color of 10 honey samples collected in the state of Bahia and their activity against three species of bacteria: Escherichia coli, Pseudomonas aeruginosa and Staphylococcus aureus. The antibacterial potential was verified in all samples and a significant relationship between color and microbial activity against Staphylococcus aureus was obtained, reinforcing the hypothesis that darker honeys tend to have greater antibacterial potential.
\end{abstract}

Additional key words: Apis mellifera, bactericidal, resistance.

Resultado da desidratação e transformação do néctar a partir da combinação com substâncias próprias das abelhas, o mel é uma mistura de carboidratos, ácidos orgânicos, aminoácidos, proteínas, vitaminas, lipídios, compostos aromáticos, flavonoides, grãos de pólen e outras substâncias menos frequentes (AlmeidaMuradian et al. 2013; Israili 2014; Rao et al. 2016). Diretamente relacionadas à sua composição química, as propriedades biológicas do mel variam com as espécies florais da qual se originam (Kolayli et al. 2013; Rao et al. 2016). A composição do mel também pode variar de acordo com a espécie de abelha produtora, conferindo-lhe características específicas (Mendes et al. 2009; Israili 2014; Lira et al. 2014; Almasaudi et al. 2017).

$\mathrm{O}$ aspecto sensorial de maior importância na aceitabilidade do mel é a coloração (Lacerda et al. 2010; Rocha et al. 2010; Jesus et al. 2014). Essa é uma das características que mais atraem o consumidor, com grande relevância no mercado internacional (Mendes et al. 2009). A coloração do mel está relacionada com a origem floral, o processamento, o armazenamento e a fatores climáticos (Smith 1967; Moreti et al. 2006; Abadio Finco et al. 2010; Vieira et al. 2014). Acreditase que minerais estejam entre os fatores responsáveis pela cor dos méis, observando-se que quanto maior a

\footnotetext{
*Autora para correspondência: algnascim@gmail.com;

a raquelgb@gmail.com

Editor responsável: Alessandro Rapini

Submetido: 6 ago. 2020; aceito: 2 abr. 2021

Publicação eletrônica: 6 abr. 2021; versão final: 8 abr. 2021
}

quantidade de minerais, mais escuro será o mel (Alves et al. 2005). Além do armazenamento prolongado, a luz, o aquecimento e a colheita também podem escurecer o mel (Alves et al. 2005).

A cor do mel pode variar de branco-água a âmbarescuro, passando por extra branco, branco, extra âmbarclaro, o âmbar-claro ao âmbar (Rocha et al. 2010; Peralta et al. 2015). No mercado mundial, a cor do mel é um fator determinante. Méis mais claros são os preferidos pelos consumidores, consequentemente, possuem um valor comercial agregado maior (Sodré 2005; Lacerda et al. 2010; Rocha et al. 2010; Jesus et al. 2014). No entanto, os méis escuros são mais ricos em sais minerais, em vitaminas $\mathrm{B}$ e $\mathrm{C}$, e possuem um aroma mais acentuado que os méis de cor clara (Lacerda et al. 2010; Rocha et al. 2010; Vieira et al. 2014).

Usado por milênios na medicina tradicional, o mel é referido como uma alternativa de uso para fins medicinais e antibacterianos para diversos tipos de cepas, entre elas Escherichia coli, Pseudomonas aeruginosa e Staphylococcus aureus (Grzegozeski 2015; Peralta et al. 2015; Medeiros et al. 2016; Amaral et al. 2017). Os componentes antimicrobianos do mel possuem múltiplos sítios de ação contra bactérias e fungos, diferenciando-se dos antibióticos e antifúngicos no mercado, que detêm apenas um sítio de ação contra determinado microrganismo (Maddocks \& Jenkins 2013; Almasaudi et al. 2017). A habilidade do mel em eliminar ou controlar esses microrganismos é atribuída a inúmeros fatores, entre eles a presença de fenóis, flavonoides e terpenos (Molan 1992; Mulu et al. 2004; Montenegro \& Mejías 2013; Israili 2014; Rao 2016). 
Desde que a utilização de antibióticos foi amplamente difundida, há cinco décadas, as bactérias têm desenvolvido gradativamente resistência. Esta resistência bacteriana aos antibióticos é uma constante preocupação na área da saúde (WHO 2001). Por essa razão, estudos têm buscado desenvolver compostos que possam ser usados com finalidade antimicrobiana além da terapia antibiótica convencional (Borsato et al. 2009). O estado da Bahia é deficiente em estudos acerca do mel. Embora existam estudos sobre a qualidade e composição do mel na região (Oliveira 2009; Lacerda et al. 2010; CastroFilho et al. 2017), ainda são escassas as pesquisas que avaliaram sua atividade antimicrobiana (Lucchese et al. 2006; Peralta et al. 2015). Assim, nosso objetivo principal aqui foi identificar a atividade antibacteriana de diferentes méis produzidos por Apis mellifera L., buscando avaliar uma possível relação entre as cores do mel e seu potencial antibacteriano.

\section{Metodologia}

Amostras. Foram utilizadas dez amostras de mel produzido por Apis mellifera Linnaeus, 1758 (Hymenoptera: Apidae) no estado da Bahia (M1-M10). As amostras pertencem a nove municípios: Conceição do Coité (M3), Feira de Santana (M6), Ipupiara (M2), Juazeiro (M9), Queimadas (M8), Serrinha (M10), Uauá (M4), Valente (M1) e Capela do Alto Alegre (M5 e M7), este último com duas amostras. Os méis foram adquiridos em pontos comerciais e com produtores, entre agosto e outubro de 2019. Todas as amostras foram acondicionadas em geladeira até o início dos testes.

Microrganismos. Os microrganismos utilizados no estudo foram obtidos na Coleção de Cultura de Microrganismos da Bahia, Universidade Estadual de Feira de Santana (CCMB/UEFS). São cepas-padrão das espécies Escherichia coli (CCMB261), Pseudomonas aeruginosa (CCMB268) e Staphylococcus aureus (CCMB262).

Determinação da cor. A cor das amostras de mel foi determinada com um espectrofotômetro ajustado em $560 \mathrm{~nm}$, usando células de $1 \mathrm{~cm}$, utilizando glicerina pura como branco. A leitura foi comparada à escala de cores de Pfund (Brasil 1981). Amostras com valores $\leq 0,44 \mathrm{~nm}$ foram classificadas como mel claro e $>0,44 \mathrm{~nm}$, como mel escuro. Todas as amostras foram testadas em triplicata, obtendo-se a média da absorbância.

Concentração inibitória mínima (CIM). A técnica de microdiluição foi utilizada para estimar a CIM do mel contra as bactérias estudadas, segundo os protocolos e adaptações propostos pela Clinical and Laboratory Standards Institute - CLSI (2003; 2012). Para o teste, foram pesadas $5 \mathrm{~g}$ de cada amostra, que foram diluídas em $5 \mathrm{~mL}$ de água destilada autoclavada e filtrada com membrana de celulose estéril $(0,22 \mu \mathrm{m})$, resultando em uma solução com concentração de 50\% (1000 mg.mL). A suspensão bacteriana foi padronizada em solução salina $(0,85 \%)$ com turvação de 0,5 na escala McFarland.

Em uma microplaca de titulação com 96 poços e fundo em forma de "U" (fabricante KASVI) foram acrescidos $150 \mu \mathrm{L}$ de caldo Müller-Hinton (CMH) e 150 $\mu \mathrm{L}$ de cada amostra de mel realizando a diluição seriada em oito concentrações: $500 \mathrm{mg} \cdot \mathrm{mL}, 250 \mathrm{mg} \cdot \mathrm{mL}, 125$ mg.mL, 62,5 mg.mL, 31,3 mg.mL, 15,6 mg.mL, 7,8 mg.mL e 3,9 mg.mL. Após a diluição, foram aplicados $20 \mu \mathrm{L}$ da suspensão bacteriana, apresentando ao final $47,5 \%(\mathrm{v} / \mathrm{v})$ de mel. As placas foram homogeneizadas e levadas à estufa a $37^{\circ} \mathrm{C}$ por $24 \mathrm{~h}$. Após o período de incubação, foi acrescido $10 \mu \mathrm{L}$ do revelador cloreto de 2,3,5-trifeniltetrazólio (TTC) a 0,5\% em cada poço, esperando-se $3 \mathrm{~h}$ para a leitura dos resultados, em que o transparente caracteriza a inatividade bacteriana e a cor vermelha/rosa, a atividade.

Como controle positivo para crescimento bacteriano foi utilizado $150 \mu \mathrm{L}$ do meio de cultura e $20 \mu \mathrm{L}$ da suspensão bacteriana; nos controles negativos, foram utilizados $150 \mu \mathrm{L}$ do meio de cultura com $20 \mu \mathrm{L}$ do antibiótico gentamicina $40 \mathrm{mg} . \mathrm{mL}(\mathrm{GEN})$ e $20 \mu \mathrm{L}$ da suspensão, bem como $150 \mu \mathrm{L}$ do meio de cultura $(\mathrm{CMH})$ puro. Foram realizadas triplicatas para confirmação dos resultados.

Concentração bactericida mínima (CBM). A determinação da CBM foi realizada após o crescimento bacteriano nas microplacas. Antes da adição do revelador, em cada poço que a olho nu não era observado crescimento bacteriano, como turvação no poço, foram retiradas três alíquotas de $20 \mu \mathrm{L}$ cada e despejadas em três placas de Petri com Ágar MüllerHinton (AMH), sendo espalhada por toda a placa com a ajuda de cotonetes estéreis. Posteriormente, foi adicionado o revelador nas microplacas e levadas à estufa, como citado acima. As placas para observação de crescimento bacteriano foram incubadas em estufa $\left(37^{\circ} \mathrm{C}\right)$ e, após o período de $24 \mathrm{~h}$, foi verificado se havia crescimento bacteriano ou se a concentração testada tinha efeito bactericida.

Análise estatística. Os resultados dos testes aplicados foram submetidos à análise estatística do coeficiente de correlação (rs) Spearman, utilizando o parâmetro da coloração e as concentrações inibitórias mínimas das amostras contra os microrganismos estudados no programa Paleontology Statistics Software Package for Education and Data Analysis (PAST) versão 2.17 (Hammer et al. 2001).

\section{RESUltados}

Coloração. A análise da cor dos méis demonstrou a média da absorbância das amostras variando entre extra âmbar-claro $(0,121-0,188 \mathrm{~nm})$, âmbar-claro $(0,189$ $0,440 \mathrm{~nm})$ e âmbar-escuro $(>0,946)$. Cinco amostras foram classificadas como âmbar escuro, representando $50 \%$ do total, seguidas por três como âmbar claro (30\%) e duas como extra âmbar claro (20\%). 
Microdiluição em caldo. $\mathrm{Na}$ técnica de microdiluição em caldo para determinar CIM e CBM, todas as amostras apresentaram atividade antibacteriana frente à Pseudomonas aeruginosa (Tabela 1). Das dez amostras, oito tiveram ação bactericida: M1 (500 mg.mL), M2 (250 mg.mL), M3 (250 mg.mL), M4 (250 mg.mL), M5 (500 mg.mL), M7 (500 mg.mL), M8 (500 mg.mL) e M10 (500 mg.mL). Todas as amostras tiveram concentrações bacteriostáticas de $250 \mathrm{mg} . \mathrm{mL}$, 125 mg.mL, 125 mg.mL, 125 mg.mL, 250 mg.mL, 250 mg.mL, 250 mg.mL, 250 mg.mL, 500 mg.mL e 250 mg.mL, respectivamente.
Escherichia coli foi sensível para oito das dez amostras testadas (Tabela 1). As amostras M2 e M4 apresentaram atividade bactericida nas concentrações 500 mg.mL e 250 mg.mL e bacteriostática em 250 mg.mL e $125 \mathrm{mg} . \mathrm{mL}$, respectivamente. Já as amostras M1, M3, M5, M6, M8 e M10, demonstraram apenas atividade bacteriostática na concentração $500 \mathrm{mg} \cdot \mathrm{mL}$. Para Staphylococcus aureus, apenas a amostra M4 foi bactericida na concentração 250 mg.mL e bacteriostática em $125 \mathrm{mg} \cdot \mathrm{mL}$, e as amostras M2, M6, M8 e M10 foram bacteriostáticas na concentração 500 mg.mL (Tabela 1).

Tabela 1. Valores de absorbância (Abs) e de concentração inibitória mínima (CIM) e bactericida mínima (CBM) das amostras de mel produzidas pela abelha Apis mellifera no estado da Bahia entre agosto e outubro de 2019 contra as bactérias Escherichia coli, Pseudomonas aeruginosa e Staphylococcus aureus.

\begin{tabular}{lccccccc}
\hline Coloração & \multicolumn{2}{c}{ Escherichia coli } & \multicolumn{2}{c}{ Pseudomonas aeruginosa } & \multicolumn{2}{c}{ Staphylococcus aureus } \\
Abs56 $(\mathrm{nm})$ & $\begin{array}{c}\text { CIM } \\
(\mathrm{mg} . \mathrm{mL})\end{array}$ & $\begin{array}{c}\mathrm{CBM} \\
(\mathrm{mg} \cdot \mathrm{mL})\end{array}$ & $\begin{array}{c}\text { CIM } \\
(\mathrm{mg} . \mathrm{mL})\end{array}$ & $\begin{array}{c}\text { CBM } \\
(\mathrm{mg} . \mathrm{mL})\end{array}$ & $\begin{array}{c}\text { CIM } \\
(\mathrm{mg} . \mathrm{mL})\end{array}$ & $\begin{array}{c}\text { CBM } \\
\text { (mg.mL) }\end{array}$ \\
\hline M1 & 0,154 & 500 & - & 250 & 500 & - & - \\
M2 & 2,327 & 250 & 500 & 125 & 250 & 250 & - \\
M3 & 0,131 & 500 & - & 125 & 250 & - & 250 \\
M4 & 2,500 & 125 & 250 & 125 & 250 & 125 & - \\
M5 & 0,215 & 500 & - & 250 & 500 & - & - \\
M6 & 1,646 & 500 & - & 250 & - & 500 & - \\
M7 & 0,207 & - & - & 250 & 500 & - & - \\
M8 & 1,061 & 500 & - & 250 & 500 & 500 & - \\
M9 & 0,327 & - & - & 500 & - & - & - \\
M10 & 2,021 & 500 & - & 250 & 500 & 250 & - \\
\hline
\end{tabular}

- concentração mínima não determinada entre as concentrações testadas.

Análise estatística. A correlação entre absorbância e CIM dos méis foi significativa contra $S$. aureus $[(\mathrm{rs})=$ $0,8834 \mathrm{e}(\mathrm{p})=0,0006]$ : quanto mais escuro o mel, menor a concentração inibitória mínima contra o microrganismo. Essa correlação, no entanto, não foi significativa contra $E$. coli $[-0,0297(\mathrm{p})=0,9349]$ e $P$. aeruginosa $[-0,1468(\mathrm{p})$ $=0,6856]$ (Figura 1$)$.

\section{DisCUSSÃo}

Nossos resultados indicaram uma correlação entre a coloração e a atividade microbiana das amostras de méis, ainda que ela tenha sido estatisticamente significativa apenas frente à bactéria Staphyloccocus aureus, mas não para Escherichia coli e Pseudomonas aeruginosa. Méis mais escuros, portanto, apresentaram maior capacidade de inibição de S. aureus. A amostra M4 foi a única bactericida para os três microrganismos na concentração de $250 \mathrm{mg} . \mathrm{mL}$, sendo a amostra mais escura do estudo, com $\mathrm{ABS}_{560}=2,500 \mathrm{~nm}$. Peralta (2010) sugeriu que essa relação entre cor e atividade biológica poderia estar associada aos teores de minerais ou compostos do metabolismo secundário das plantas constituintes do mel. A maior resistência de $E$. coli e $P$. aeruginosa (bactérias Gram-negativas) a antimicrobianos quando comparadas a S. aureus (Gram-positiva) pode ser causada pela baixa permeabilidade da membrana plasmática composta por lipopolissacarídeos (Slama 2008; Peralta et al. 2015) e pela bomba de efluxo, um 

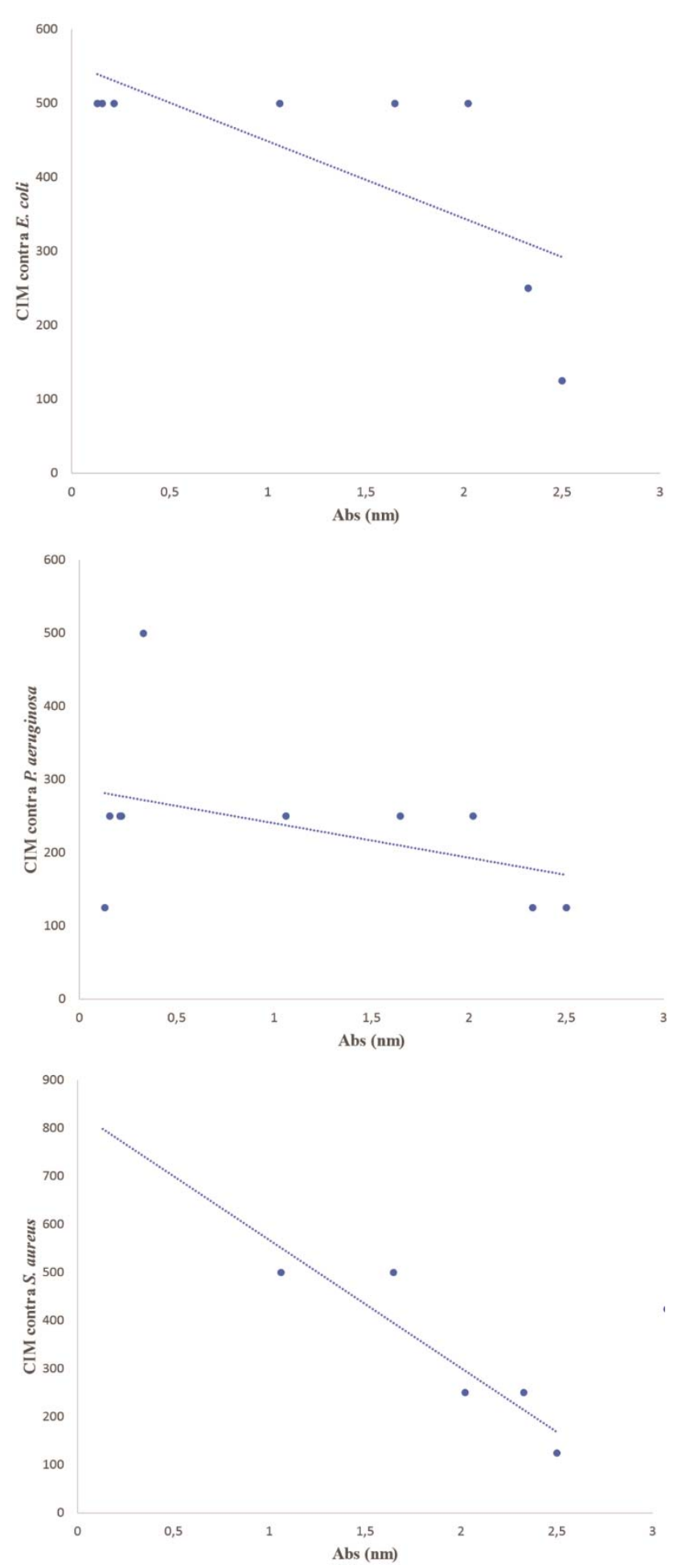

Figura 1. Relação entre absorbância (Abs) e concentração inibitória mínima (CIM) de méis de A. melifera do estado da Bahia contra Escherichia coli, Pseudomonas aeruginosa e Staphylococcus aureus (Tabela 1).

mecanismo especializado que expulsa substâncias estranhas da célula (Slama, 2008; Mercês et al. 2013).

Os resultados deste estudo estão de acordo com outras pesquisas que mostraram a eficácia do mel, mesmo na concentração de $50 \% \quad(\mathrm{v} / \mathrm{v})$ contra microrganismos (Almasaudi et al. 2017; Hawkins 2015; Peralta et al. 2015). Como já relatado, os méis mostraram efeito tanto contra bactérias Gram-positiva como Gram-negativas. Neste estudo, cada microrganismo mostrou uma sensibilidade diferenciada às amostras, variando de altamente sensível (Pseudomonas aeruginosa) a menos sensível (Staphylococcus aureus). Pseudomonas aeruginosa foi sensível a todos os méis testados, que portanto apresentaram efeito bactericida e/ou bacteriostático. Neves et al. (2011), Lucchese et al. (2006) e Peralta et al. (2015) já haviam relatado a grande sensibilidade de $P$. aeruginosa a méis de $A$. mellifera. Escherichia coli foi a segunda bactéria mais sensível neste estudo, sendo inibida por oito das dez amostras. Pseudomonas aeruginosa e E. coli têm mostrado maior resistência a antimicrobianos quando comparadas a Staphyloccocus aureus devido à natureza Gram-negativa desses microrganismos (Slama 2008; Peralta et al. 2015), e Peralta et al. (2015) observaram que ambas foram menos inibidas por méis classificados como âmbarescuro. Nossos resultados, no entanto, indicaram que o crescimento de $P$. aeruginosa e E. coli foi inibido por todos ou quase todos os méis amostrados na Bahia, sejam eles claros ou escuros, diferente de $S$. aureus, que por apresentar correlação com a coloração dos méis, foi sensível apenas para cinco amostras, as mais escuras.

$\mathrm{O}$ mel possui inúmeras atividades biológicas, bioquímicas e fisiológicas e a eficácia das propriedades presentes no mel depende de sua composição. Diferentes tipos de mel têm sido investigados quanto às suas propriedades antimicrobianas, anticâncer, antidiabéticas, anti-inflamatórias, antioxidantes e cicatrizantes. As informações fornecidas aqui evideciam a necessidade de avaliações sobre as atividades biológicas e os potenciais do mel. Estudos futuros devem se concentrar no uso de méis no combate à resistência antimicrobiana, uma vez que este produto se encontra disponível na maior parte do país e é relativamente barato em comparação com antibióticos convencionais. Além disso, os estudos devem identificar a composição dos méis, incluindo análises palinológicas e de metabólitos secundários, para determinar os fatores responsáveis pela sua atividade antimicrobiana.

\section{AGRADECIMENTOS}

Agradecemos o apoio do Laboratório de Pesquisa em Microbiologia (LAPEM) da Universidade Estadual de Feira de Santana (UEFS) e do Conselho Nacional de Desenvolvimento Científico e Tecnológico (CNPq).

\section{REFERÊNCIAS}

Abadio Finco, F.D.B.; Moura, L.L. \& Silva, I.G. 2010 Propriedades físicas e químicas do mel de Apis mellifera L. Ciência e Tecnologia de Alimentos 30: 706-7 12.

Almasaudi, S.B.; Al-Nahari, A.A.M.; Abd El-Ghany, E.M.; Barbour, E.; Al Muhayawi, S.M.; Al-Jaouni, S.; Azhar, E.; Qari, M.; Qari, Y.A. \& Harakeh, S. 2017. Antimicrobial effect 
of different types of honey on Staphylococcus aureus. Saudi Journal of Biological Sciences 24: 1255-1261.

Almeida-Muradian, L.B.; Stramm, K.M.; Horita, A.; Barth, O.M.; Freitas, A.S. \& Estevinho, L.M. 2013. Comparative study of the physicochemical and palynological characteristics of honey from Melipona subnitida and Apis mellifera. International Journal of Food Science and Technology 48: 1698-1706.

Alves, R.M.O.; Carvalho, C.A.L.; Souza, B.A.; Sodré, G.S. \& Machini, L.C. 2005. Características físico-químicas de amostras de mel de Melipona mandacaia Smith (Hymenoptera: Apidae). Ciência e Tecnologia de Alimentos 25: 644-650.

Amaral, T.Y; Padilha, I.G.; Presídio, G.A.; Silveira, E.A.A.S.; Duarte, A.W.F.; Barbosa, A.P.F.; Bezerra, A.F.S. \& López, A.M.Q. 2017. Antimicrobial and anti-inflammatory activities of Apis mellifera honey on the Helicobacter pylori infection of Wistar rats gastric mucosa. Food Science and Technology 37: 34-41.

Borsato, D.M.; Cruz, M.C.R. \& Almeida, M.M. 2009. Atividade antimicrobiana de méis comercializados na região dos Campos Gerais - Paraná. Visão Acadêmica 10(1).

Brasil. 1981. Métodos analíticos oficiais para controle de produtos de origem animal e seus ingredientes: métodos físicos e químicos. Laboratório Nacional de Referência Animal (LANARA). Portaria ${ }^{\circ} 01$, de 07 de outubro de 1981. Ministério da Agricultura. Secretaria Nacional de Defesa Agropecuária Diário Oficial da União, Brasília - DF. Disponível em: http:/extranet.agricultura.gov.br/sislegisconsulta/servlet/Visuali zarAnexo?id=13362. Acesso em: 21 jan. 2019.

Castro-Filho, M.N.; Santos, J.L.; Paes, E.C.; Dias, W.S.R. \& Pereira, L.F. 2017. Avaliação da qualidade de méis de abelha produzidos e comercializados em Vitória da Conquista, Bahia. Revista Verde 12: 783-790.

CLSI (Clinical and Laboratory Standards Institute) 2003. Performance Standards for Antimicrobial Disk Susceptibility Tests. Approved Standard -8 ed. NCCLS document M2-A8, Wayne, USA

CLSI. (Clinical and Laboratory Standards Institute) 2012. Methods for Dilution Antimicrobial Susceptibility Tests for Bacteria That Grow Aerobically. Approved Standard - 9 ed. CLSI document M07-A9, Wayne, USA.

Grzegozeski, T.L. 2015. Influência da Espécie de Abelha e da Origem Floral do Mel sobre a Atividade Antimicrobiana frente às Bactérias Staphylococcus aureus e Escherichia coli. Trabalho de Conclusão de Curso. Departamento Acadêmico de Ambiental, Universidade Tecnológica Federal do Paraná, Campo Mourão.

Hammer, O.; Harper, D.A.T. \& Ryan, P.D. 2001. PAST: Paleontological Statistics Software Package for Education and Data Analysis. Palaeontologia Electronica 4: 1-9.

Hawkins, J. 2015. Investigating Antibacterial Plant-Derived Compounds from Natural Honey. PhD Thesis. School of Pharmacy and Pharmaceutical Sciences, Cardiff University.

Israili, Z.H. 2014. Antimicrobial properties of honey. American Journal of Therapeutics 21: 304-323.

Jesus, M.C.; Borges, R.L.B.; Souza, B.A.; Brandão, H.N. \& Santos, F.A.R. 2014. A study of pollen from light honeys produced in Piauí State, Brazil. Palynology 39: 110-124.

Kolayli, S.; Yildiz, O.; Sahin, H. \& Aliyazicioglu, R. 2013. Biochemistry and physicochemical properties of honey. In: L. Boukraâ (ed.), Honey in Traditional and Modern Medicine. CRC Press, New York, p. 21-35.
Lacerda, J.J.J.; Santos, J.S.; Santos, S.A.; Rodrigues, G.B. \& Santos, M.L.P. 2010. Influência das características físicoquímicas e composição elementar nas cores de méis produzidos por Apis mellifera no sudoeste da Bahia utilizando análise multivariada. Quimica Nova 33: 1022-1026.

Lira, A.F.; Sousa, J.P.L.M.; Lorenzon, M.C.; Vianna, C.A.F.J. \& Castro, R.N. 2014. Estudo comparativo do mel de Apis mellifera com méis de meliponíneos. Acta Veterinaria Brasilica, 8: 169178.

Lucchese, A.M.; Uetanabaro, A.P.T.; Peralta, E.D.; Machado, S.S.; Campos, O.M. \& Magalhaes, R.C. 2006. Méis do Semiárido: composição química e atividade antimicrobiana. In: F.A.R. Santos, A.M. Giulietti, L.P. Queiroz. (orgs), Apium Plantae. Associação Plantas do Nordeste, Recife, p. 119-130.

Maddocks, S. \& Jenkins, R. 2013. Honey: a sweet solution to the growing problem of antimicrobial resistance? Future Microbiology 8: 1419-1429.

Medeiros, V.F.L.P.; Azevedo, I.M.; Rêgo, A.C.M.; Egito, E.S.T.; Araújo-Filho, I \& Medeiros, A.C. 2016. Antibacterial properties and healing effects of Melipona scutellaris honey in MRSA-infected wounds of rats. Acta Cirúrgica Brasileira 31: 327-332.

Mendes, C.G.; Silva, J.B.A.; Mesquita, L.X. \& Maracajá, P.B. 2009. As análises de mel: revisão. Caatinga 22: 7-14.

Mercês, M.D.; Peralda, E.D.; Uetanabaro, A.P.T. \& Lucchese, A.M. 2013. Atividade antimicrobiana de méis de cinco espécies de abelhas brasileiras sem ferrão. Ciência Rural 43: 672-675.

Molan, P.C. 1992. The antibacterial activity of honey. Bee world 73: $5-28$.

Montenegro, G. \& Mejías, E. 2013. Biological applications of honeys produced by Apis mellifera. Biological Research 46: 341-345.

Moreti, A.C.C.C.; Sodré, G.S.; Marchini, L.C. \& Carvalho, C.A.L. 2006. Cor de amostras de mel de Apis mellifera L. de diferentes estados brasileiros. Boletim de Indústria animal 63: 159-164.

Mulu, A.; Tessema, B. \& Derbie, F. 2004. In vitro assessment of the antimicrobial potential of honey on common human pathogens. Ethiopian Journal of Health Development 18: 107-112.

Neves, P.R.; Mamizuka, E.M.; Levy, C.E. \& Lincopan, N. 2011. Pseudomonas aeruginosa multirresistente: um problema endêmico no Brasil. Jornal Brasileiro de Patologia e Medicina Laboratorial 47: 409-420.

Oliveira, P.P. 2009. Análise Palinológica de Amostras de Mel de Apis mellifera L. Produzidas no Estado da Bahia. Tese (Doutorado em Botânica) - Programa de Pós-Graduação Em Botânica, Universidade Estadual de Feira de Santana, Feira de Santana.

Peralta, E.D. 2010. Atividade Antimicrobiana e Composição Química de Méis do Estado da Bahia. Tese (Doutorado em Biotecnologia) - Programa de Pós-Graduação em Biotecnologia, Universidade Estadual de Feira de Santana, Feira de Santana.

Peralta, E.D.; Uetanabaro, A.P.T. \& Lucchese, A.M. 2015. Méis do semiárido baiano: atividade antimicrobiana e composição química. In: F.A.R. Santos \& C.E. Carneiro (orgs), De Melle Semiaridi: analisando o mel nordestino. EDUFBA, Salvador, p. 121-169.

Rao, P.V.; Krishnan, K.T.; Salleh, N. \& Gan, S.W. 2016 Biological and therapeutic effects of honey produced by honey 
bees and stingless bees: a comparative review. Revista Brasileira de Farmacognosia 26: 657-664.

Rocha, H.C.; Lara, A.A.; Cecchetti, D. \& Pacheco, A.B. 2010. Características físico-químicas de méis produzidos em favos de diferentes idades. Ciências Agrárias 31: 639-644.

Slama, T.G. 2008. Gram-negative antibiotic resistance: there is a price to pay. Critical Care 12: S4.

Smith, F.G. 1967. Deterioration of the color of honey. Journal of Apicultural Research 6: 95-98.

Sodré, G.S. 2005. Características físico-químicas, microbiológicas e polínicas de amostras de méis de Apis mellifera L., 1758 (Hymenoptera: Apidae) dos estados do Ceará e Piauí. Tese
(Doutorado em Ciências) - Escola Superior de Agricultura "Luiz de Queiroz", Universidade de São Paulo, Piracicaba.

Vieira, A.C.; Delonzek, E.C.; Lüdke, M.V.; Breyer, D. \& Lorscheider, C.A. 2014. Caracterização físico-química de mel de diferentes floradas produzido por apicultores orgânicos da região centro-sul e sudeste no estado do Paraná. Acta Iguazu 3: 138-148.

WHO (World Health Organization) 2001. Global Strategy for Containment of Antimicrobial Resistance. Disponível em: $<$ https://apps.who.int/iris/bitstream/handle/10665/66860/WHO_ CDS_CSR_DRS_2001.2.pdf;jsessionid=1BC28943489AF66A9 AD35EC9EC63F1BD?sequence=1>. Acesso em: 10 mar. 2019. 